\title{
Characterizing the intermetallic formed during ball attach process
}

Paulo Pereira *, Rúben Santos *, Maria M. Barbosa *, Cátia Almeida *

* Dep. de Engenharia Metalúrgica e de Materiais, Faculdade de Engenharia, Universidade do Porto, Rua Dr. Roberto Frias, 4200-465 Porto, Portugal

Continuously miniaturization of electronic components using PCB's technology for the manufacturing of SDRAM's uses a solder ball attach process, producing a joint which robustness and electrical response are crucial factors to success. At present, near-eutectic Sn$\mathrm{Ag}-\mathrm{Cu}$ alloys are the leading candidates for Pb-free solders. According to Chun et al. [1], the rapid formation of $\mathrm{Cu}-\mathrm{Sn}$ intermetallic compounds at the interface affects the reliability of this solder joint and represents a major concern. In this study we characterize the interface of an attachment between the copper layer conductors of a memory and a solder ball which allows further bonding to printed circuit modules, see figure 1.a.

The attachment uses a $10 \mu \mathrm{m}$ thick intermediate layer of nickel deposited over a copper pad and protected by a thin gold film. The solder, with a spherical shape and composition of Sn$1.0 \mathrm{Ag}-0.5 \mathrm{Cu}$, is placed on the gold film and the assemblage is heated up to the brazing temperature. This process diffuses the gold into the solder ball and produces an intermetallic compound of $\mathrm{Sn}-\mathrm{Ni}-\mathrm{Cu}$, between the nickel and the solder ball with 1 to $2 \mu \mathrm{m}$ thickness as seen on figure $1 . b$.

Analysing our experimental EDS data, and accordingly to the $240^{\circ} \mathrm{C}$ isothermal section of the ternary phase diagram $\mathrm{Sn}-\mathrm{Ni}-\mathrm{Cu}$, the compound formed is either $(\mathrm{Cu}, \mathrm{Ni})_{6} \mathrm{Sn}_{5}$ or $(\mathrm{Ni}, \mathrm{Cu})_{3} \mathrm{Sn}_{4}$. Similar results were found in other studies [1,2]. During attach process, the $\mathrm{Cu}$ atoms in the solder arrive at the solder/Ni interface, causing the formation of a Ni-containing $\mathrm{Cu}_{6} \mathrm{Sn}_{5}$ $\left((\mathrm{Cu}, \mathrm{Ni})_{6} \mathrm{Sn} 5\right)$. In this case, the composition of the intermetallic was 20.3 at.\% $\mathrm{Cu}, 13.2$ at.\% $\mathrm{Ni}, 62.9$ at.\% $\mathrm{Sn}$ and 3.6 at.\% $\mathrm{Au}$ (figure 2.a). Some particles with this chemical composition were also observed at inner zones of the solder ball (see arrow on figure 1b), indicating a preferential copper and nickel diffusion path inside the ball once it allows higher diffusion kinetics during ball attach process. Some other particles composed by tin, silver, copper and gold were found near the interface zone (figure 2.b).

Nanoindentation tests were performed using AFM equipment. An AFM image of the indentations is shown on figure 3. The indentation depth variation between $\mathrm{Sn}$ braze alloy and intermetallic layer clearly states that the intermetallic is significantly harder than the braze alloy.

[1] H. Chun, J. Yoon and S. Jung - Solid-state interfacial reactions between Sn-3.5Ag-0.7Cu solder and electroless Ni-immersion Au substrate during high temperature storage test, Journal of Alloys and Compounds 439 (2007) 91-96;

[2] A. Kumar, Z. Chen - Influence of solid-state interfacial reactions on the tensile strength of Cu/electroless $\mathrm{Ni}-\mathrm{P} / \mathrm{Sn}-3.5 \mathrm{Ag}$ solder joint, Materials Science and Engineering A 423 (2006) 175-179.

Acknowledgement

The materials characterized in this work were kindly supplied by Qimonda Portugal S.A.

${ }^{* *}$ The authors are students of the Master in Metallurgical and Materials Engineering. 


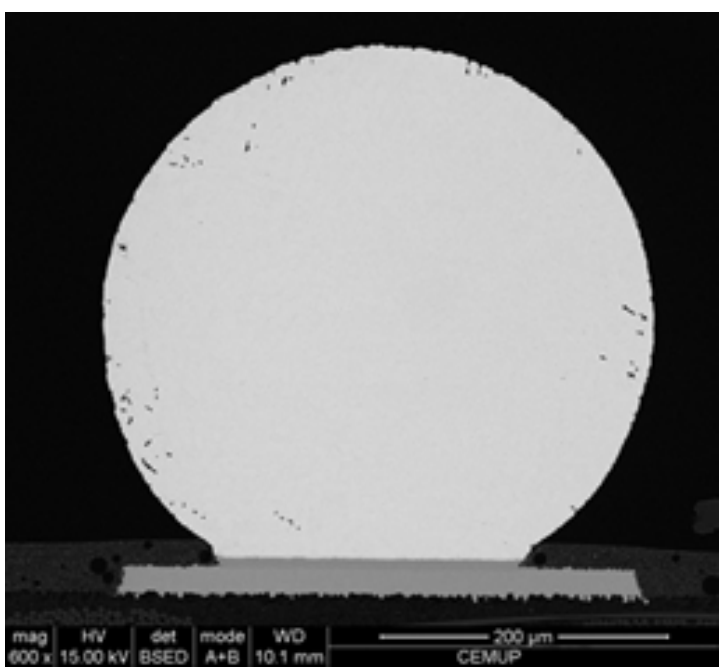

Fig.1.a)

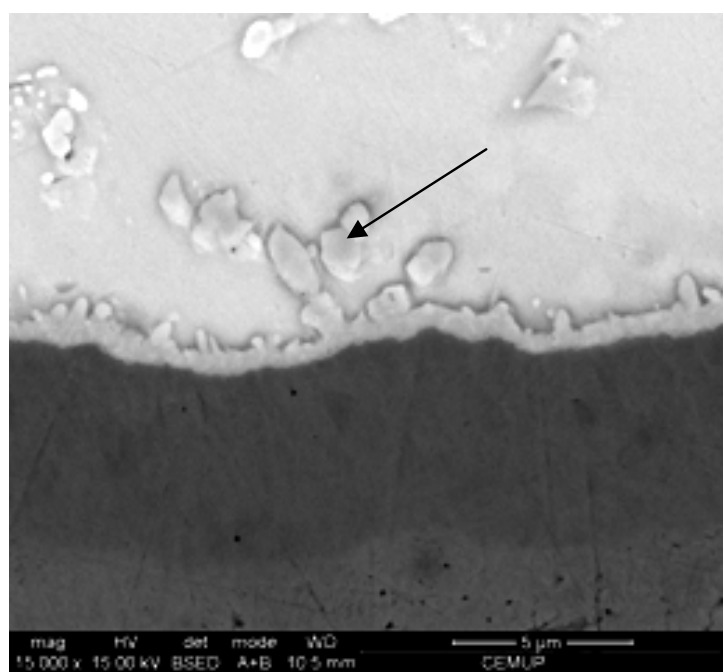

Fig.1.b)

Figure 1. SEM image of: (a) the ball attach bonding; (b) the interface showing the intermetallic compound formed between the $\mathrm{Ni}$ (darker layer) and the $\mathrm{Sn}$ braze alloy (lighter area).

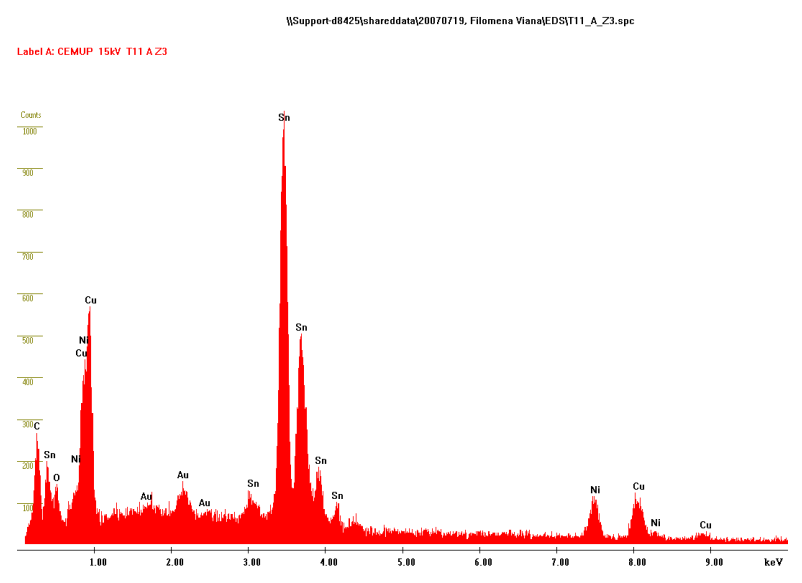

Fig.2.a)

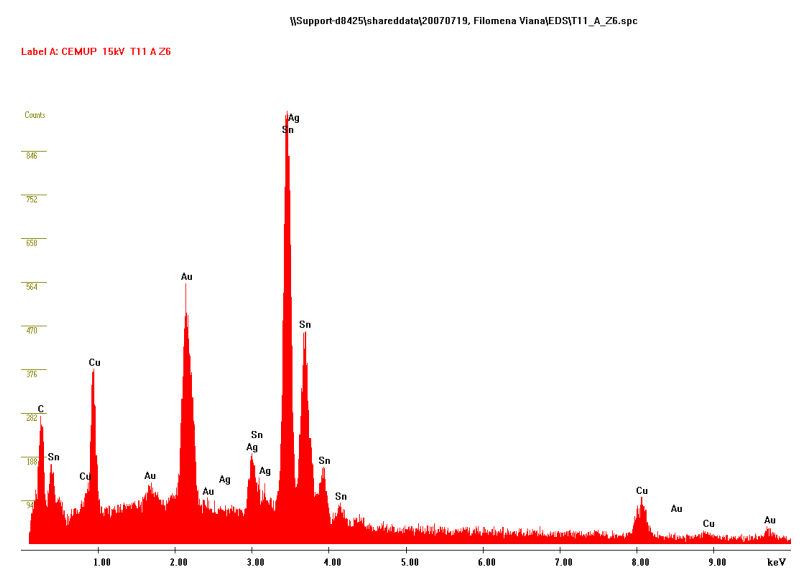

Fig.2.b)

Figure 2. EDS spectrum for: (a) intermetallic zone; (b) the lighter particles on fig.1.b.

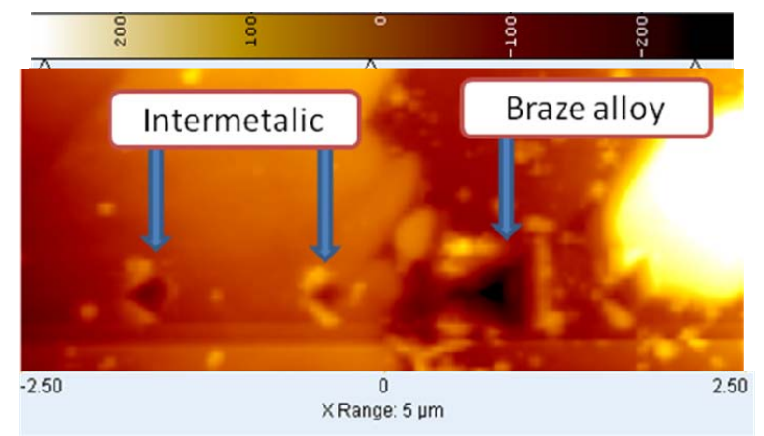

Figure 3. AFM image of the indentations in the braze alloy and intermetallic compound. 